\title{
Balkanologie
}

Balkanologie Revue d'études pluridisciplinaires

Vol. XIII, $n^{\circ} 1-2$ | 2011

Volume XIII Numéro 1-2

\section{Roth (Klaus) and Brunnbauer (Ulf) eds, Urban Life and Culture in Southeastern Europe. Anthropological and Historical Perspectives}

Ethnologia Balkanica 10 (2006) - Munich, LMU, 2006, 365 p.

Hugues Sachter

\section{OpenEdition}

Journals

Édition électronique

URL : http://journals.openedition.org/balkanologie/2309

DOI : 10.4000/balkanologie.2309

ISSN : 1965-0582

Éditeur

Association française d'études sur les Balkans (Afebalk)

Référence électronique

Hugues Sachter, «Roth (Klaus) and Brunnbauer (UIf) eds, Urban Life and Culture in Southeastern Europe. Anthropological and Historical Perspectives », Balkanologie [En ligne], Vol. XIII, n 1-2 | 2011, mis en ligne le 16 décembre 2011, consulté le 17 décembre 2020. URL : http://journals.openedition.org/ balkanologie/2309; DOI : https://doi.org/10.4000/balkanologie.2309

Ce document a été généré automatiquement le 17 décembre 2020.

(c) Tous droits réservés 


\section{Roth (Klaus) and Brunnbauer (Ulf) eds, Urban Life and Culture in Southeastern Europe. Anthropological and Historical Perspectives}

Ethnologia Balkanica 10 (2006) - Munich, LMU, 2006, 365 p.

Hugues Sachter

\section{RÉFÉRENCE}

Roth (Klaus) and Brunnbauer (Ulf) eds, Urban Life and Culture in Southeastern Europe. Anthropological and Historical Perspectives, Ethnologia Balkanica 10 (2006) - Munich, LMU, $2006,365 \mathrm{p}$.

1 L'ouvrage collectif en question constitue un événement considérable, tant par le nombre des contributions (22) que par l'aire géographique concernée (presque tous les pays de l'Europe du Sud Est, y compris la Slovénie, mais hors Bosnie-Herzégovine, Kosovo et Monténégro). Les contributions sont réparties en cinq chapitres, à savoir :

- -Structure et planification urbaines, architecture (5 articles)

--Relations ville-campagne (2 articles)

- -Topographie sociale, relations ethniques et de genre (4 articles)

- -Culture urbaine, urbanité (4 articles)

- -La culture populaire dans la ville (6 articles)

Dans le premier chapitre, Maximilan Hartmuth étudie de manière transversale l'émergence d'un langage architectural post-ottoman au début du $\mathrm{XX}^{\circ}$ siècle, alors que l'Empire perd son hégémonie et qu'une prétention généralisée à une modernité fait renaître l'identité nationale. Marija Maksin-Mićić étudie la constitution des périphéries urbaines de Valjevo et Knjaževac en Serbie, en insistant sur le rapport balancé à la ruralité et à la centralité qui s'y forme. Katarina Višnar s'intéresse pour sa part au 
devenir des signes résiduels de la ruralité une fois ceux-ci insérés dans un tissu urbain (sur le cas de Ljubljana). Ermis Lafazanovski met en évidence le basculement des lieux publics de Skopje, et les modifications du statut de la grande place face au vieux pont, de la conquête serbe de 1912 à l'après-tremblement de terre de 1963, au niveau des pratiques sociales $\mathrm{du}$ centre-ville. Cristofer Scarboro étudie les monuments révolutionnaires de Haskovo (Bulgarie), et les glissements de style et de sens qui s'y manifestent au fur et à mesure que l'on y est passé d'un socialisme héroïque et guerrier à un socialisme humaniste prétendant au bien-être.

3 Dans le deuxième chapitre, Konstantina Bada rend compte d'une enquête sur le devenir des femmes venues à la ville, à Agrinio, en Grèce du Nord, mettant en évidence les circonstances (faisant une large part à la guerre civile et aux coupures conséquentes) et les dynamiques d'émancipation par l'activité économique qui s'en sont suivies. Rory Yeoman offre une étude approfondie et balancée du rapport ambivalent entre ville ( $a$ priori décadente car cosmopolite) et campagne (affublée de l'image de la pureté originelle) que présente l'évolution de la pensée oustachi en Croatie entre les deux guerres.

4 Dans le troisième chapitre, Siegfried Gruber étudie les ségrégations spatiales (sociales et religieuses) dans le Shkodër de 1918. Mirjana Pavlović se penche quant à elle sur l'ethnicité des Serbes de Timisoara, qu'elle relie principalement à une vision d'immigration rurale en quête de statut. Ana Luleva et Cvetana Bončeva explorent la construction des identités dans le contexte d'une zone frontalière entre Bulgarie et Grèce, au travers des comportements d'identification liés à l'usage des stéréotypes dans les mariages mixtes. Ivanka Petrova étudie les rôles sexués dans une grande entreprise internationale à Sofia, dans laquelle les marqueurs de genre, souvent associés à des stéréotypes de société traditionnelle, structurent les rapports dans l'entreprise au-delà des prescriptions organisationnelles. Aleksandar Miletić revient sur la culture urbaine dans l'entre-deux-guerres dans le Royaume de Yougoslavie, en mettant en évidence au travers d'une revue de presse une modernisation urbaine, marquée par un affranchissement au regard des rapports patriarcaux, confrontée à un grave problème de logement et d'urbanisation, et sans cesse refoulée par l'opinion publique encore profondément liée à la prégnance du monde rural. L'article d'Ivana Spasić se réfère au thème omniprésent de l'« asphalte » (ASFALT) comme signifiant (en général positif) de l'urbain en Serbie, en affirmant une filiation à la notion bourdieusienne de distinction. $\mathrm{Au}$ fil des interviews cette notion s'affirme comme le thème central d'une opposition à la culture rurale, ou plus exactement à la culture urbaine enracinée dans le rural telle qu'elle s'est manifestée avec acuité dans la Serbie de la période Milošević. Vesna Vučinić-Nešković et Jelena Miloradović produisent une analyse de sociologie urbaine du Corso (Korzo) de Smederevska Palanka (Serbie), appuyée sur une microgéographie des lieux de déroulement de ce cérémonial urbain, élevé au rang (justifié à notre avis) de phénomène social total. Aleksandra Pavićević clôt le chapitre avec une réflexion historique de l'émergence de la crémation comme rite funéraire urbain dans la Serbie en voie de modernisation, rappelant les présupposés hygiénistes d'origine et les obstacles, moins purement religieux que liés à la perpétuation des rites funéraires.

5 Le quatrième chapitre s'ouvre avec un article d'Ivana Kronja sur les tendances de la culture urbaine en Serbie à partir de la fin du régime communiste. La vie de café et les thématiques du cinéma social mettent en avant l'influence écrasante des médias dans la nouvelle culture, qui façonne ainsi les rôles sociaux qui se mettent en scène dans la vie 
de loisirs, tandis que la débrouille et la «ligne de moindre résistance » conduisent des existences sans ligne de force. Dragana Antonijević et Ljubomir Hristić analysent le discours des graffiti dans Belgrade, alternant entre protestations contre le régime Milošević, l'intolérance ethnique et sexuelle pour aboutir aux slogans philosophiconihilistes. Mais ces expressions peuvent être reclassées en expressions conservatrices et expressions de révolte, mettant néanmoins au premier plan la sublimation de la violence par l'identification aux groupes de supporters. Orli Fridman présente le phénomène des « femmes en noir » sur ce lieu politiquement symbolique qu'est la Place de la République à Belgrade. Le mouvement face à la responsabilité et à l'oubli (Srebrenica), est plus audible sur le lieu du crime, mais n'y trouve pas à se confronter au champ politique serbe, comme c'est le cas en ce lieu de confrontation des discours. Ana Hofman et Iva Tarabić s'interrogent sur une expérience d'échanges de cultures musicales avec les musiciens rroms, mettant en évidence les différents types de musiques et d'instruments en lien avec la professionnalisation, puis avec la commercialisation de la profession sur le mode moderne du show biz, qui permet une identification aux musiques vernaculaires non rroms. Dans le même registre, Raluca Nagy et Cristina Plecadite décrivent le développement de la musique techno (" électronique ») à Bucarest, comme signe d'intégration au monde extérieur de la part des jeunes, avec en particulier l'émergence des clubs comme points de rassemblement corrélativement à celle de la figure du DJ. C'est à la nouvelle sociabilité de café à Constantza que s'intéresse Raluca Petre, constatant l'élargissement des cercles de sociabilité par rapport au peu de mobilité sociale qu'imposait la rigidité des sociétés socialistes. Enfin, Iva Filipova Kyurcheva prend en considération les pratiques politiques associées aux clubs de football, dans la période de fin du communisme, comme dans les premières années de transition, se référant à la ligne d'E. Hobsbawn concernant la substitution du sport à la religion dans le contexte d'éveil des nationalismes.

6 La première constatation que l'on peut faire est que l'ensemble de la zone des Balkans est balayée et que, bien que les spécificités de chaque pays puissent être savourées par le connaisseur, la réalité commune aux sociétés contemporaines de l'Europe du Sud-Est est bien cernée. En définitive, on se doit de constater que le classement par chapitres est relativement artificiel, et pourrait subir un système de rotations et d'inversions quasi infini. Mais en fait, la thématique d'ensemble reprend les grands thèmes récurrents de la littérature balkanique qui associent le doublet ville-campagne et celui de tradition-modernité, mais une fois de plus sans que les deux oppositions soient bien distinguées. Sur le plan de la méthode, on constate l'irruption généralisée des méthodes contemporaines d'ethnologie et de micro-géographie urbaines, qui confèrent leur qualité aux travaux empiriques. Par contre, sur le plan théorique, on sent que la primauté va à la problématique «balkanique» comme spécificité, alors que la contribution au débat théorique entre courants de pensée ne vient qu'en second rang. Cette impression est confirmée par la place relativement faible qu'occupe la sortie du socialisme dans les problématiques, même si cette dernière constitue la toile de fond inévitable des phénomènes décrits dans cet ouvrage. 


\section{AUTEURS}

HUGUES SACHTER

Maître de conférences en Économie à l'Université d'Artois 